Lankhorst, K., Takken, T., Zwinkels, M., Gaalen, L. van, Velde, S. te, Backx, F., Verschuren, O., Wittink, H., Groot, J. de. Sports Participation, Physical Activity, and Health-Related Fitness in Youth With Chronic Diseases or Physical Disabilities: The Health in Adapted Youth Sports Study. Journal of Strenght and Conditioning Research: 2019, 35(8), p. 2327-2337

$\begin{array}{lll}\text { Postprint version } & : & 2.0 \\ \text { Journal website } & : & \text { https://insights.ovid.com/crossref?an=00124278-900000000-94896 } \\ \text { Pubmed link } & : & \text { https://www.ncbi.nlm.nih.gov/pubmed/31210643 } \\ \text { DOI } & : \text { doi: 10.1519/JSC.0000000000003098 }\end{array}$

This is a Nivel certified Post Print, more info at nivel.nl

\title{
Sports Participation, Physical Activity, and Health-Related Fitness in Youth With Chronic Diseases or Physical Disabilities: The Health in Adapted Youth Sports Study
}

\author{
Kristel Lankhorst, ${ }^{1,2}$ Tim Takken, ${ }^{3}$ Maremka Zwinkels, ${ }^{2,4}$ Leendert van Gaalen, ${ }^{1}$ \\ Saskia te Velde, ${ }^{1}$ Frank Backx, ${ }^{2}$ Olaf verschuren, ${ }^{4}$ Harriet Wittink, ${ }^{1}$ Janke de \\ Groot $^{1,3,5}$
}

\begin{abstract}
${ }^{1}$ Research Group Lifestyle and Health, Institute of Human Movement Studies, University of Applied Sciences, Utrecht, the Netherlands; ${ }^{2}$ Department of Rehabilitation, Physical Therapy Science and Sports, Brain Center Rudolf Magnus, University Medical Center Utrecht, Utrecht, the Netherlands; ${ }^{3}$ Child Development and Exercise Center, Wilhelmina Children's Hospital, University Medical Center Utrecht, Utrecht, the Netherlands; ${ }^{4}$ Center of Excellence in Rehabilitation Medicine, Brain Center Rudolf Magnus, University Medical Center Utrecht, and De Hoogstraat Rehabilitation, Utrecht, the Netherlands; and ${ }^{5}$ Netherlands Institute for Healthcare Services Research
\end{abstract}

(NIVEL), Utrecht, the Netherlands

\begin{abstract}
Lankhorst, K, Takken, T, Zwinkels, M, van Gaalen, L, Velde, St, Backx, F, Verschuren, O, Wittink, $\mathrm{H}$, and de Groot, J. Sportsparticipation, physical activity, and health-related fitness in youth with chronic diseases or physical disabilities: the health in adaptedyouth sports study. J Strength Cond Res XX(X): 000-000, 2019-Youth with chronic diseases or physical disabilities (CDPD) oftenshow reduced fitness and physical activity (PA) levels and participate less in organized sports compared with healthy peers. Thepurpose of this study was to examine the associations between participation in sports and healthrelated fitness and PA in youthwith CDPD. A total of 163 participants (mean age 14 years; range 8-19 years) with CDPD were included in this cross-sectionalstudy, with 81 participating in organized sports and 82 not. Participants were recruited between October 2014 and November2016. Aerobic and anaerobic fitness, agility, and muscle strength were assessed in the laboratory, whereas PA was monitored indaily life using accelerometry during 1 week. Linear regression analyses were used to assess the associations of sports participation(independent variable) with health-related fitness and PA (dependent variables). Results show that youth with CDPD participating
\end{abstract}


Lankhorst, K., Takken, T., Zwinkels, M., Gaalen, L. van, Velde, S. te, Backx, F., Verschuren, O., Wittink, H., Groot, J. de. Sports Participation, Physical Activity, and Health-Related Fitness in Youth With Chronic Diseases or Physical Disabilities: The Health in Adapted Youth Sports Study. Journal of Strenght and Conditioning Research: 2019

inorganized sports 2 times a week performed better on all outcome measures. They reached a higher peak oxygen uptake (differenceof $4.9 \mathrm{ml} \mathrm{O}_{2} \cdot \mathrm{kg}^{-1} \cdot \mathrm{min}^{-1}, P=0.001$ ) compared with their peers not participating in sports. Also, anaerobic fitness, agility, musclestrength, and PA were all positively associated with sports participation. Moreover, the association between sports participationand aerobic fitness was mediated by PA for $31 \%(P=0.045)$. In conclusion, participation in sports is associated with both higherlevels of PA and health-related fitness in youth with CDPD. Promotion and stimulation of participation in sports seems a good way topromote health-related fitness as well as a healthy active lifestyle in youth with CDPD.

\section{Introduction}

Youth with chronic diseases or physical disabilities (CDPD) have lower fitness levels (45), lower levels of physical activity (PA) $(12,36)$, and a higher prevalence of adiposity (29) than their healthy peers. The detrimental health effects of physical inactivity in healthy youth are well established $(15,27,30)$. In healthy youngsters, insufficient PA levels are highly associated with low cardiorespiratory fitness, higher levels of obesity, and increased cardiovascular risk $(26,39)$.

Many studies have reported the benefits of sports in promoting PA $(28,46)$ and its contribution of moderate-to-vigorous PA (MVPA) to daily recommended PA in healthy youth (44). The current recommendations for youth (5-17 years), including those with CDPD, state that they should accumulate at least 60 minutes of MVPA daily for healthy development or 20 minutes of vigorous physical activity (VPA) for at least 3 timesweekly to achieve the same health effect $(9,11)$. Shorter exercise time with a higher intensity (VPA) support sports participation to meet PA guidelines and to develop a healthy active lifestyle.

Although the health benefits related to sports and PA have been reported in healthy youth, there is only limited evidence as to what extent sports participation may affect PA and health-related fitness in youth with CDPD. A recent study did report a significant correlation between aerobic fitness and cardiovascular health and also an inverse relationship between adiposity and cardiovascular health in youth with CDPD (20). Finding ways to improve health-related fitness and cardiovascular health therefore seems an important goal for youth with CDPD. At the same time, training studies have shown that youth with CDPD indeed can improve their PA level and health-related fitness through supervised intervention programs in rehabilitation settings $(18,45)$. However, the positive results achieved are often not maintained in the longer term after these programs end $(13,49)$. Weekly participation in sports could be, based on what we know in healthy youth, a solution to maintain and optimize PA levels and health-related fitness in youth with CDPD.

Arecent study showed that youthwithCDPDoften do not meet the guidelines for healthy PA. While already difficult for healthy peers to meet recommended levels of PA, a Dutch publication showed that youthwithCDPDparticipate even less in competitive and recreational sports $(9,10)$. Only $26 \%$ of youth with CDPD participate in sports once a week (10) compared with $71 \%$ of their healthy peers (9).

Although this low adherence to PA guidelines might be detrimental to health-related fitness and physical functioning, several studies have reported important barriers for youth with CDPD making it difficult to participate in sports. These barriers include both personal factors, e.g., the lack of energy, fatigue, and lack of "leisure" time due to longer school hours and more time spent in activities of daily living, and environmental factors $(10,25)$. The latter includes accessibility of the physical environment but also attitudes from the social environment, e.g., parents, teachers, health care professionals and policy makers, including fear of injury, thinking sports might be too difficult, lack of knowledge regarding the importance of PA for youth with CDPD, or more practical considerations such as transportation to an adapted sport facility (53). To overcome some of these social barriers, 
Lankhorst, K., Takken, T., Zwinkels, M., Gaalen, L. van, Velde, S. te, Backx, F., Verschuren, O., Wittink, H., Groot, J. de. Sports Participation, Physical Activity, and Health-Related Fitness in Youth With Chronic Diseases or Physical Disabilities: The Health in Adapted Youth Sports Study. Journal of Strenght and Conditioning Research: 2019

research is needed showing that there are positive associations between sports participation and health-related fitness. With this knowledge, attitudes might change toward the importance of sports participation for youth with CDPD.

We hypothesize that youth with CDPD who participate in sports are more active and show better health-related fitness outcomes than those who are not. Therefore, the aim of this study was to investigate the associations of sports participation with health-related fitness and PA in youth with CDPD.

\section{Methods}

\section{Experimental Approach to the Problem}

This study is part of the larger Health in Adapted Youth Sports (HAYS) study. We used a crosssectional prospective design to investigate the associations of sports participation with physical fitness, PA, cognition, cardiovascular health, and quality of life in youth with CDPD. The current article focuses on the associations of sports participation with PA and health-related fitness in youth with CDPD. The associations of sport participation with self-perception, exercise self-efficacy, and quality of life were published previously (43). All assessments were performed between October 2014 and November 2016. A detailed description of the research design and testing procedures has been published previously (31). An overview of the outcome measures and used measurement instruments of the current study are summarized in Table 1.

\section{[Table 1]}

\section{[Table 2]}

\section{[Table 3]}

\section{Subjects}

Participants were eligible for this study when they were ambulatory, aged from 8 up to 19 years with CDPD and diagnosed with cardiovascular, pulmonary, musculoskeletal, metabolic, or neuromuscular disorder. Table 2 shows the eligibility and exclusion criteria. The characteristics of the participants such as age, sex, medical diagnosis, identification of sports participation, and nonsport are displayed in Table 3. The medical diagnoses were further classified into categories according to the American College of Sports Medicine (Table 3) (17).

Written informed consent was provided by all participants and as required by Dutch law also by the parents of participants younger than 18 years. In line with Dutch law, no parental informed consent was required for participants 18 years and older. This study was approved by the Medical Ethics Committee of the University Medical Center Utrecht, the Netherlands (METC number: 14$332 / c)$.

\section{Procedures}

Independent Variable: Sports Participation. Sports participation was identified using 3 standardized questions used by the National Institute for Public Health and the Environment (RIVM) (24): (a) do you participate in organized sports?, (b) what is/are the type of organized sport(s)?, and (c) what is the frequency of participation in organized sports per week? When participants were involved in organized sports at least 2 times per week, they were classified as the "sports group" (SG), and all others were classified as the "non"sporting group (NSG). 
Lankhorst, K., Takken, T., Zwinkels, M., Gaalen, L. van, Velde, S. te, Backx, F., Verschuren, O., Wittink, H., Groot, J. de. Sports Participation, Physical Activity, and Health-Related Fitness in Youth With Chronic Diseases or Physical Disabilities: The Health in Adapted Youth Sports Study. Journal of Strenght and Conditioning Research: 2019

\section{Dependent Variables.}

Physical activity and health-related fitness including cardiovascular health and physical fitness were assessed (Table 1). Measurement instruments and tests that were valid and reliable in children and adolescents with physical disabilities were used. Specific details about the validity and reliability of the measurement instruments and tests were described in detail previously (31). One week before the testing session, the general questionnaire was completed by the participant. Each assessment was performed using a standardized test protocol. All measurements related to health-related fitness took place on 1 day and were performed in the following order: height and body mass, bioelectric impedance analysis, waist and hip circumference measurements, arteriograph measurement, grip strength, standing broad jump, 103 5-m sprint, muscle power sprint test (MPST), and cardiopulmonary exercise test. Finally, the use of the PA monitor and activity diary was explained to the participant for the PA monitoring in the home situation (Table 1). In general, instructions were given by the researcher and if needed a practice session took place before the actual test started. When this was the case, the participant received sufficient rest before the actual test took place. Between each test, there was time for recovery. In addition, the researchers asked the participants after each test and recovery period if the participant felt ready to continue the test protocol; if not, further resting was allowed. The extra need of recovery was determined by the participant.

\section{Health-Related Fitness: Cardiovascular Health.}

Height and body mass were measured, and body mass index (BMI) was calculated using body mass $(\mathrm{kg}) /$ body height ${ }^{2}(\mathrm{~m})$. For waist and hip circumference, a measure in standing position was taken at the umbilicus and trochanter major, and waist/hip ratio was defined. To control for differences in age, $\mathrm{Z}$ scores of body height, body mass, BMI, waist and hip circumference, and waist/hip ratio were calculated according to Dutch reference values (42). Fat mass was measured in supine position with bioelectrical impedance analysis (Bodystat Quadscan 4000; EuroMedix, Leuven, Belgium).

Arterial stiffness was determined by aortic pulse wave velocity (PWVao), as a measure of arterial stiffness, and augmentation index (AIX\%), as a measure of peripheral arterial tone. The measurements were performed in a supine position after ten-minute rest by a noninvasive oscillometric tonometry device (Arteriograph; TensioMed, Ltd, Budapest, Hungary) at the right arm. A higher PWVao indicates a higher aortic stiffness, and a higher AIX\% indicates a higher peripheral arterial tone. Blood pressure (systolic and diastolic) and resting heart rate were also measured using the Arteriograph within the same measurement. Instructions to the subject were no food intake 3 hours before measurement and no talking during the measurement. After the measurement of arterial stiffness, the child was allowed to eat something, before continuation of the other tests.

\section{Physical Fitness}

To test the strength of the subjects, tests from the Brockport fitness test were chosen (57). The isometric muscle strength was tested through the use of a handheld hydraulic dynamometer (5).The participants' dominant hand was tested, and one practice session took place before the actual test started. Mean grip strength was calculated out of 3 attempts.

The standing broad jump was used to evaluate the explosive strength of the lower limbs by measuring the distance jumped with 2 legs together from the standing position (14). Mean distance was calculated of 3 trials and used for analysis. One practice session took place before the actual test started.

Agility was measured using the 1035 -m sprint test (50) and also valid for use in children and adolescents with and without a pathological gait pattern (56). During this test, the child was asked to sprint as fast as possible, 10 times, in between 2 lines that were 5-m apart. There was no resting period, so the child/adolescent had to turn as fast as possible during this test. Time was recorded using a stopwatch. Anaerobic fitness was determined by the MPST, which has been validated for use 
Lankhorst, K., Takken, T., Zwinkels, M., Gaalen, L. van, Velde, S. te, Backx, F., Verschuren, O., Wittink, H., Groot, J. de. Sports Participation, Physical Activity, and Health-Related Fitness in Youth With Chronic Diseases or Physical Disabilities: The Health in Adapted Youth Sports Study. Journal of Strenght and Conditioning Research: 2019

in children and adolescents with and without a pathological gait pattern $(16,41,50,54)$. Subjects had to complete six $15-\mathrm{m}$ runs at a maximum pace. One sprint was performed by the participant for practice, before the actual test started. The MPST is an intermittent sprint test, in which the child stops and starts at standardized intervals. Power was calculated ([body mass 3 distance]2/time3) for each of the 6 sprints, and mean power was defined as the average power over the 6 sprints and used for further analysis.

Aerobic fitness was determined using an incremental exercise test. In exercise testing, peak oxygen uptake ( $\dot{\mathrm{V}}_{2}$ peak) is considered to be the single best indicator of cardiorespiratory fitness or aerobic fitness. A cardiopulmonary exercise testing system, the Cortex Metamax 3X(Samcon bvba, Melle, Belgium), was used for evaluation of the respiratory gasses and $\mathrm{V}_{2}$ peak. Aerobic fitness was assessed by an adapted 10-m incremental shuttle run test (48) or by an incremental exercise test on an electronically braked cycle ergometer (Ergoline, Ergoselect $200 \mathrm{~K}$; Ergoline, Bitz, Germany). In persons with disability, the main mode of locomotion/mobility elicits the highest $\dot{\mathrm{VO}}_{2}$ peak (6). Therefore, the type of sports or daily locomotion determined whether the shuttle run test or a cycling ergometry test was used. In children with a congenital cardiopulmonary disease, a cycling test was always used, because of the electrocardiography monitoring of the heart for safety issues.

The speed of the shuttle run test was adjusted based on the results of the MPST and the agility test. The cycling test, using the Godfrey protocol (19), was used to test the aerobic fitness in children who are active on a bike in sports or daily living. Load depended on the height of the child and the expected level of fitness. Regardless of the testing modality, the test started with a resting measurement for 3 minutes. Participants were verbally encouraged to keep on exercising until voluntary exhaustion. Exercise tests were considered maximal and included for analysis if 2 out of 3 of the following criteria were achieved: (a) peak heart rate $.180 \mathrm{~b} \cdot \mathrm{min}^{-1}$, (b) peak respiratory exchange ratio.1.0, or (c) subjective signs of exhaustions (out of breath, sweating, or plateau of $\dot{\mathrm{V}}{ }^{2}$ ) or unable to continue the test (52). Cardiorespiratory fitness was defined as $\dot{V}^{2}$ peak per body mass and $\dot{V}^{2}$ peak in liter per minute, and to control for differences in age, $Z$ scores of $\dot{V O}^{2}$ peak were calculated according to Dutch reference values (8).

\section{Physical Activity}

Physical activity was measured using an activity monitor, the Activ8 (2M Engineering BV,

Valkenswaard, the Netherlands). The Activ8 is a valid one-sensor ambulatory monitoring system and has been validated for use in youth with and without motor impairments (32). Each subject wore the sensor on the dominant leg, fixed with a Tegaderm (3M, Delft, the Netherlands) waterproof skin tape during 7 consecutive days for 24 hours each day. To calculate and interpret the data of waking hours gathered with the activity monitor, sleeping time was recorded in a diary. A minimum of 1 weekend day and 2 school days with a minimum of 600 minutes per day were required for further analysis (35). The time in minutes per day were calculated for each activity (lying, sitting, standing, walking, bicycling, and running) during awake hours and calculated for school and weekend days separately. The PA data were divided into sedentary and active categories. Sedentary activity consisted of lying and sitting, whereas active activities entailed walking, bicycling, and running.

\section{Power Analysis}

The sample size of the HAYS study was based on a study of Verschuren and Takken (47). In this study, children and adolescents with cerebral palsy (CP) had aVO ${ }^{2}$ peak of $42 \mathrm{ml} \mathrm{O}_{2} \cdot \mathrm{kg}^{-1} \cdot \mathrm{min}^{-1}(S D \pm 8.2)$. To prove a difference of $10 \%$ between the SG and NSG, with an alpha of 0.05 and beta of 0.20 (power of 0.80 ), a sample size of 66 subjects per group was required. When taking a failure rate of $10 \%$ into account, a minimum of 146 subjects were required in total. 
Lankhorst, K., Takken, T., Zwinkels, M., Gaalen, L. van, Velde, S. te, Backx, F., Verschuren, O., Wittink, H., Groot, J. de. Sports Participation, Physical Activity, and Health-Related Fitness in Youth With Chronic Diseases or Physical Disabilities: The Health in Adapted Youth Sports Study. Journal of Strenght and Conditioning Research: 2019

\section{Statistical Analyses}

All analyses were performed using the SPSS Statistics, Version 23.0 (IBM, Corp., Armonk, NY, USA). First, descriptive statistics was used to describe the outcomes in the 2 groups. Independent Student's t-tests, the Mann-Whitney U-test, and the chi-square test were used to determine the differences between the SG and NSG. Linear regression analyses were used to assess the relationship between sports participation (independent variable) with health-related fitness and PA (dependent variables). Assumptions regarding normality of residuals were checked and met the assumptions. The regression models were adjusted for potential confounders such as age, sex, and diagnosis.

To determine whether the association between sports participation and the primary outcome variable $\dot{V} \mathrm{O}^{2}$ peak was mediated by $\mathrm{PA}$, mediation regression analyses were conducted using the product-of-coefficient method (Figure 1 and Table 8) (21). First, the overall relationship between participation in sports and the outcome variable $\dot{V}^{2}$ peak was estimated (the $C$ coefficient). Second, the relationship between participation in sports and the potential mediator variables, the 2 categories: (M1) sedentary and (M2) active, was estimated (the A coefficient). Third, the relationship between the mediator variables and the outcome $\dot{V}^{2}$ peak was estimated (the B coefficient). Finally, the effect of participation in sports on $\mathrm{VO}^{2}$ peak adjusted for the mediator was estimated (the $\mathrm{C} 9$ coefficient or mediator-adjusted effect). The proportion of the total effect of participation in sports on the $\dot{V O}^{2}$ peak measure that was mediated by any of the potential mediators tested was also calculated (dividing the mediated effect by the total effect [A coefficient $3 \mathrm{~B}$ coefficient/C coefficient]). Mediation was considered partial when the mediator-adjusted association between participation in sports and the outcome (the C9 coefficient) remained significant. The PROCESS module in SPSS was used to conduct the mediation analyses (22). The mean time in minutes of the total week (school and weekend days) for the clustered categories sedentary and active was calculated and used for this mediation regression analyses. For each coefficient estimated, $95 \%$ bootstrapped confidence intervals ( $\mathrm{Cls}$ ), $\mathrm{p}$ values, and adjusted $\mathrm{R}$ square were calculated. A $\mathrm{p}$ value \#0.05 was considered statistically significant.

\section{[Figure 1]}

\section{[Table 4]}

\section{Results}

\section{Participants' Characteristics}

A total of 163 ambulatory participants with CDPD were included for this study between September 2014 and October 2016 (96 boys [mean age 14.3 years, $S D \pm 2.8$ ] and 67 girls [mean age 14.2 years, $\mathrm{SD} \pm 3.0]$ ). Descriptive statistics of the sample are presented in Table 3.

\section{Health-Related Fitness}

Youth who participated in sports had a significant higher $\dot{V} \mathrm{O}^{2}$ peak, had a higher power on the MPST, were faster on the 1035 -m sprint test, had a higher mean grip strength, and were able to jump horizontally further compared with the NSG (Table 4). In addition, the participants in the SG had a significant lower waist/hip circumference ratio SDS and lower percentage of fat mass compared with the NSG (Table 4). There were no significant differences between participants in the SG and NSG for blood pressure (systolic and diastolic), resting heart rate, and the arterial stiffness (PWV and AIX) (Table 4). The number of participants who performed an incremental shuttle run test or an incremental exercise test on a cycle ergometer was equally distributed between the NSG and SG. 
Lankhorst, K., Takken, T., Zwinkels, M., Gaalen, L. van, Velde, S. te, Backx, F., Verschuren, O., Wittink, H., Groot, J. de. Sports Participation, Physical Activity, and Health-Related Fitness in Youth With Chronic Diseases or Physical Disabilities: The Health in Adapted Youth Sports Study. Journal of Strenght and Conditioning Research: 2019

\section{[Physical Activity}

Youth participating in sports were more active than those who did not during both school and weekend days. The mean total minutes of bicycling and running were significantly higher for the SG compared with the NSG (Table 5). In addition, the total active time (walking, bicycling, and running) was significantly higher in the SG compared with the NSG. Sedentary time (lying and sitting) did not significantly differ between the groups during both the weekend and school days (Table 5).

\section{[Table 5]}

\section{[Table 6]}

\section{Sports Participation Associated With Health-Related Fitness}

Sports participants showed a higher $\dot{V} \mathrm{O}^{2}$ peak. We found significant positive associations for both boys and girls between participation in sports and $\dot{V}^{2}$ peak. Boys had a higher $\dot{V}^{2}$ peak compared with girls. The effect of sports participation was independent of the medical diagnosis (Table 6).

The mean power on the MPST, the time on the $1035-\mathrm{m}$ sprint test, the mean grip strength, and the mean standing broad jump were all positively associated with sports participation (Table 6). Overall, participation in sports, sex, and age were associated with a better performance on all these outcome measurements. Participants with a pathological gait pattern scored lower on all outcomes (see motoric gait function, Table 6).

Youth participating in sports had a lower percentage of fat mass compared with peers not participating in sports (Table 6).Youth with a pathological gait pattern had a significantly higher percentage of fat and higher waist/hip circumference SDS. Sports participation, sex, and age were positively associated with the waist/hip circumference SDS.

\section{Sports Participation Associated With Physical Activity}

Sports participation was positively associated with the amount of active time during both school and weekend days (Table 7). Age was negatively associated with the amount of active time during weekend days. Participants with a pathological gait pattern spent a lower number of minutes in active time during school days compared with peers without a pathological gait pattern.

Sports participation was positively associated with both bicycling and running during school days. The motoric gait function was negatively associated with bicycling, whereas sex and age were negatively associated with running during school days. In addition, sports participation was positively associated with bicycling during weekend days, whereas age was negatively associated with bicycling. Youth in the SG ran more in the weekend compared with peers from the NSG.

\section{[Table 7]}

\section{Mediation Regression Analysis}

Physical activity mediated the association between sports participation and $\dot{V}^{2}{ }^{2}$ peak (Table 8 ). The mediating effect of PA on $\dot{V O}^{2}$ peak was $0.033 \mathrm{mlO}_{2} \cdot \mathrm{kg}^{-1} \cdot \mathrm{min}^{-1}$. For every additional minute of PA, $\dot{V} O^{2}$ peak increased with $0.033 \mathrm{ml} \cdot \mathrm{kg}^{-1} \cdot \mathrm{min}^{-1}$. The proportion mediated was $31 \%$. Sedentary time did not mediate the association between sports participation and $\dot{\mathrm{VO}}^{2}$ peak. 
Lankhorst, K., Takken, T., Zwinkels, M., Gaalen, L. van, Velde, S. te, Backx, F., Verschuren, O., Wittink, H., Groot, J. de. Sports Participation, Physical Activity, and Health-Related Fitness in Youth With Chronic Diseases or Physical Disabilities: The Health in Adapted Youth Sports Study. Journal of Strenght and Conditioning Research: 2019

\section{Discussion}

The results from this study demonstrate that sports participation was strongly associated with better health-related fitness and increased PA level in children and adolescents with CDPD. Youth participating at least twice weekly in organized sports performed better on all outcome measures. Our results also suggest that the association between sports participation and aerobic fitness was mediated for $31 \%$ by an increased PA level. We did not observe any significant association between sports participation and sedentary time.

We found significant positive associations for both boys and girls between participation in sports and $\dot{\mathrm{V}}_{2}$ peak. These findings are in line with current literature. Earlier studies have shown an association between fitness and sports and exercise in both girls and boys $(1,2)$. We found levels of aerobic fitness comparable with values observed in healthy youth (mean values $41.5 \mathrm{ml} \cdot \mathrm{kg}^{-1} \cdot \mathrm{min}^{-1}$ and $46-49 \mathrm{ml} \cdot \mathrm{kg}^{-1} \cdot \mathrm{min}^{-1}$ for females and males, respectively) (8). Previous studies have reported lower aerobic fitness in youth with a neuromuscular disorder $(40,51)$. A large proportion $(49.1 \%)$ in our study population consisted of participants with neuromuscular disorders. Despite this condition, sports participants with neuromuscular disorders in our study show that they can achieve $V^{2}{ }^{2}$ peak values within the normal range for healthy Dutch peers. From a health perspective, this is a remarkable and promising finding because it shows that sports seems effective in optimizing aerobic fitness and this is currently not achieved in the longer term with rehabilitation programs in youth with CDPD $(7,58)$.

Youth participating in sports also performed significantly better on outcomes of anaerobic fitness, agility, and strength measurements. Other cross-sectional studies have reported similar results with healthy peers, where their participation in recreational sports scored higher in anaerobic fitness and muscular strength than youth, those who did not (23). Short bursts of high-intensity sprints are required in youth sports, which may have resulted in a higher anaerobic fitness than their nonsporting peers. In contrast to aerobic fitness, the medical diagnosis did influence the outcomes of anaerobic fitness, agility, and muscle strength in our study. Participants with a neuromuscular disorder such as CP or spina bifida (SB) scored lower on all anaerobic fitness and performance measures compared with those without a neuromuscular disorder. These results are in line with existing evidence, which shows that a motor impairment affect anaerobic fitness negatively and the motor impairment influenced anaerobic fitness more strongly compared with aerobic fitness $(40,55)$. A muscle impairment results in a reduced muscle strength and coordination in muscles that have been affected due to the neuromuscular disorder. Because of the lower level of coordination, youth with motor impairment often need more time to complete motor tasks. Tasks including stops, turns, and accelerations, as part of the agility measures, will therefore take more time in youth with motor impairment compared to those without. Although youth with a neuromuscular disorder perform less well because of their medical condition, our study showed that participation in sports can significantly contribute to better muscle function and better performance on the anaerobic fitness and performance tests compared with their nonsporting peers with a neuromuscular disorder.

In our study, youth with CDPD who participated in sports were more active during both school and weekend days. At the same time, this higher PA level explained $31 \%$ of the association between sports participation and $\dot{V}^{2}$ peak. A total of 47 minutes more active time per week resulted in a higher $\dot{V O}^{2}$ peak of $1.55 \mathrm{ml} \cdot \mathrm{kg}^{-1} \cdot \mathrm{min}^{-1}$. In contrast to the current finding, studies in healthy youth have shown only small correlations between $\dot{V}^{2}$ peak and MVPA $(3,38)$. Youth with CDPD are less active compared with their healthy peers but do achieve positive effects on health-related fitness when they become active.

This study was the first large study to evaluate the associations between sports and health-related fitness and PA. Strong points are the objective direct measurement of both $\dot{V O}^{2}$ peak and accelerometry-based PA. Obviously, this study also has some limitations. First, the cross-sectional 
Lankhorst, K., Takken, T., Zwinkels, M., Gaalen, L. van, Velde, S. te, Backx, F., Verschuren, O., Wittink, H., Groot, J. de. Sports Participation, Physical Activity, and Health-Related Fitness in Youth With Chronic Diseases or Physical Disabilities: The Health in Adapted Youth Sports Study. Journal of Strenght and Conditioning Research: 2019

design limits the ability to establish causality and direction. At the same time, establishing associations is an important first step for further research. Second, we only included ambulatory youth with CDPD, and therefore, our results are limited to ambulatory youth with CDPD. Moreover, there were more boys in the SG compared with the NSG, which we did correct for in the statistical modeling. Sex stratification is recommended for future studies, as outcomes do differ among sex. Finally, using the standardized questionnaire on sports, we did not have information regarding the training history of the SG (e.g., how many years they have been doing sports). We only recorded whether they have participated in organized sports at least twice weekly during the past 3 months. We would recommend future research to include information of the number of years of sports participation as well as the duration, type, and characteristics of the sports activities, as it gives more insight into the long-term effects of sports. Despite these limitations, this study still demonstrates positive associations of sports participation with PA and health-related fitness independent of age, sex, and motoric gait function in ambulatory youth with CDPD.

\section{Practical Applications}

While in healthy youth only a weak relationship has been demonstrated between PA and aerobic fitness (34), PA was a strong predictor of aerobic fitness in youth with CDPD, as shown with the mediation regression analysis in our study. Our data show that youth with CDPD who participate in organized sports at least twice weekly benefit from the positive effects of sports on health-related fitness and PA. Especially in children and adolescents with CP or SB with muscle weakness, which is a major problem, organized sports contributes to a better muscular function.

As described earlier, youth with CDPD are able to improve their PA level and health-related fitness through supervised intervention programs in rehabilitation settings $(18,45)$; however, achieved results are often not maintained in the longer term $(13,49)$. Data of the current study suggest that participation in sports is an excellent way to improve or maintain health-related physical fitness in youth with CDPD.

Therefore, this study also shows it is important to focus on reducing barriers to sports participation for youth with CDPD, with special attention for girls (4) and adolescents. In this group, the drop-out from sports is high (46), PA decreases, and sedentary time increases (37). This will most likely involve a multidisciplinary approach, with professionals from the medical, social, and educational domain working together with the youth with CDPD to overcome barriers and find the possibilities to participate in sports.

For professionals, the training guidelines developed for healthy youth (33) are mostly applicable for youth with CDPD, but some characteristics and physical possibilities for certain types of sports should be taken into account. Adapted guidelines for both exercise testing and training have been published to guide coaches and trainers of the young athlete with CDPD (17). In addition, it is advisable to use relevant registration and assessment tools to monitor training loads. All measurement instruments and performance tests used in this study are feasible, easy to use, and proven valid and reliable in youth with CDPD. The measurement outcomes of all tests of the current study could be used as a reference, which makes it possible to put the test outcome of our young patient or sports participant with CDPD in perspective with their sporting and nonsporting peers.

In conclusion, participation in sports is associated with both higher levels of PA and health-related fitness in youth with CDPD. Promotion and stimulation of healthy active lifestyles including sports participation is therefore highly recommended in this special population.

\section{Acknowledgments}

The authors thank the Dutch Organization of Health Research (ZONMW) for their unconditional grant (Grant number: 525001005). And thanks to the Health in Adapted Youth Sports (HAYS) Study Group: 
Lankhorst, K., Takken, T., Zwinkels, M., Gaalen, L. van, Velde, S. te, Backx, F., Verschuren, O., Wittink, H., Groot, J. de. Sports Participation, Physical Activity, and Health-Related Fitness in Youth With Chronic Diseases or Physical Disabilities: The Health in Adapted Youth Sports Study. Journal of Strenght and Conditioning Research: 2019

FJG Backx (Department of Rehabilitation, Physical Therapy Science and Sports, Brain Center Rudolf Magnus, University Medical Center Utrecht, Utrecht, The Netherlands), JF de Groot (University of Applied Sciences, Utrecht, The Netherlands), KM Lankhorst (University of Applied Sciences, Utrecht, The Netherlands), TCW Nijboer (Brain Center Rudolf Magnus, University Medical Center Utrecht, Utrecht, The Netherlands), T Takken (Child Development and Exercise Center, University Medical Center Utrecht, Utrecht, The Netherlands), DW Smits (Brain Center Rudolf Magnus, University Medical Center Utrecht, Utrecht, The Netherlands), OW Verschuren (Brain Center Rudolf Magnus, University Medical Center Utrecht, and De Hoogstraat Rehabilitation, Utrecht, The Netherlands), JMA Visser-Meily (Department of Rehabilitation, Physical Therapy Science and Sports, Brain Center Rudolf Magnus, University Medical Center Utrecht, and De Hoogstraat Rehabilitation, Utrecht, The Netherlands), MJ Volman (Faculty of Social Sciences, Department of General and Special Education, Utrecht University, Utrecht, The Netherlands), and HW Wittink (University of Applied Sciences, Utrecht, The Netherlands).

\section{References}

1. Armstong $\mathrm{N}, \mathrm{McNarry} \mathrm{M}$. Aerobic fitness and trainability in healthy youth: gaps in our knowledge. Pediatr Exerc Sci 28: 171-177, 2016.

2. Armstrong N, Tomkinson G, and Ekelund U. Aerobic fitness and its relationship to sport, exercise training and habitual physical activity during youth. Br J Sports Med 45: 849-858, 2011.

3. Armstrong N. Aerobic fitness and physical activity in children. Pediatr Exerc Sci 25: 548-560, 2013.

4. Azevedo MR, Araujo CL, Reichert FF, Siqueira FV, da Silva MC, Hallal PC. Gender differences in leisure-time physical activity. Int J Public Health 52: 8-15, 2007.

5. Beenakker KG, Ling CH, Meskers CG, de Craen AJ, Stijnen T, Westendorp RG, et al. Patterns of muscle strength loss with age in the general population and patients with a chronic inflammatory state. Ageing Res Rev 9: 431-436, 2010.

6. Bhambhani YN, Holland LJ, and Steadward RD. Maximal aerobic power in cerebral palsied wheelchair athletes: Validity and reliability. Arch Phys Med Rehabil 73: 246-252, 1992.

7. Bloemen M, Van Wely L, Mollema J, Dallmeijer A, and de Groot J. Evidence for increasing physical activity in children with physical disabilities: A systematic review. Dev Med Child Neurol 59: 1004-1010, 2017.

8. Bongers B, Hulzebos E, van Brussel M, and Takken T. Pediatric Norms for the Cardiopulmonary Exercise Test. In: 2nd, ed. Pediatric Norms for Cardiopulmonary Exercise Testing. Den Bosch, the Netherlands: Boxpress, 2015. pp. 33-164.

9. Burghard M, Knitel K, van Oost I, Tremblay MS, and Takken T. Dutch physical activity report card study group. Is our youth cycling to health? Results from The Netherlands' 2016 report card on physical activity for children and youth. J Phys Act Health 13(11 Suppl 2): S218-S224, 2016.

10 Burghard M, Jong de N, Vlieger S, and Takken T. The Physical Activity Report Card1, on Dutch Youth with a Chronic Condition or Disability. 2017. Available at: http://www.superlab.nl/reportcarddownloads/. Accessed January 6, 2017.

11 Burghard M, de Jong NB, Vlieger S, and Takken T. 2017 Dutch report Card(1): Results from the first physical activity report card plus for Dutch youth with a chronic disease or disability. Front Pediatr 6: 122, 2018.

12. Carlon SL, Taylor NF, Dodd KJ, and Shields N. Differences in habitual physical activity levels of young people with cerebral palsy and their typically developing peers: A systematic review. Disabil Rehabil 35: 647-655, 2013. 
Lankhorst, K., Takken, T., Zwinkels, M., Gaalen, L. van, Velde, S. te, Backx, F., Verschuren, O., Wittink, H., Groot, J. de. Sports Participation, Physical Activity, and Health-Related Fitness in Youth With Chronic Diseases or Physical Disabilities: The Health in Adapted Youth Sports Study. Journal of Strenght and Conditioning Research: 2019

13. de Groot JF, Takken T, van Brussel M, Gooskens R, Schoenmakers M, Versteeg C, et al. Randomized controlled study of home-based treadmill training for ambulatory children with spina bifida. Neurorehabil Neural Repair 25: 597-606, 2011.

14. Deitz JC, Kartin D, and Kopp K. Review of the Bruininks-Oseretsky test of motor proficiency, second edition (BOT-2). Phys Occup Ther Pediatr 27: 87-102, 2007.

15. Dencker $M$ and Andersen LB. Health-related aspects of objectively measured daily physical activity in children. Clin Physiol Funct Imaging 28: 133-144, 2008.

16. Douma-van Riet D, Verschuren O, Jelsma D, Kruitwagen C, Smits- Engelsman B, Takken T. Reference values for the muscle power sprint test in 6- to 12-year-old children. Pediatr Phys Ther 24: 327-332, 2012.

17. Durstine L, Moore GE, Painter P, and Roberts SO. Considerations Regarding Physical Activity for Children and Youth. In: 3rd, ed. ACSM's Exercise Management for Persons with Chronic Diseases and Disabilities. Champaign, IL: Human Kinetics, 2009. pp. 16-22.

18. Edouard P, Gautheron V, D'Anjou MC, Pupier L, and Devillard X. Training programs for children: Literature review. Ann Readapt Med Phys, 2007;50: 510-519, 499-509.

19. Godfrey S, Davies CT, Wozniak E, and Barnes CA. Cardio-respiratory response to exercise in normal children. Clin Sci 40: 419-431, 1971.

20. Haapala EA, Lankhorst K, de Groot J, Zwinkels M, Verschuren O, Wittink H, et al. The associations of cardiorespiratory fitness, adiposity and sports participation with arterial stiffness in youth with chronic diseases or physical disabilities. Eur J Prev Cardiol 24: 11021111, 2017.

21. Hayes AF and Preacher KJ. Statistical mediation analysis with a multi-categorical independent variable. Br J Math Stat Psychol 67: 451-470, 2014.

22. Hayes AF. The Process Macro for SPSS and SAS. 2016. Available at: http://afhayes.com/ index.html. Accessed January 3, 2017.

23. Hoffman JR, Kang J, Faigenbaum AD, and Ratamess NA. Recreational sports participation is associated with enhanced physical fitness in children. Res Sports Med 13: 149-161, 2005.

24. Hollander d EL, Milder IE, and Proper KI. Exercise and Sport Behavior People with a Chronic Disorder or Physical Disability. Bilthoven, Netherlands: RIVM rapport, Ministry of Health, Welzijn \& Sport, 2015. pp. 20915-0064.

25. Jaarsma EA, Dijkstra PU, de Blecourt AC, Geertzen JH, and Dekker R. Barriers and facilitators of sports in children with physical disabilities: A mixed-method study. Disabil Rehabil 37: 16171623, 2015; quiz 1624-5.

26. Janssen I and Leblanc AG. Systematic review of the health benefits of physical activity and fitness in school-aged children and youth. Int J Behav Nutr Phys Act 7: 40, 2010.

27. Jimenez-Pavon D, Kelly J, and Reilly JJ. Associations between objectively measured habitual physical activity and adiposity in children and adolescents: Systematic review. Int J Pediatr Obes 5: 3-18, 2010.

28. Kjønniksen L, Anderssen N, and Wold B. Organized youth sport as a predictor of physical activity in adulthood. Scand J Med Sci Sports 19: 646-654, 2009.

29. Kotte EM, Winkler AM, and Takken T. Fitkids exercise therapy program in The Netherlands. Pediatr Phys Ther 25: 7-13, 2013.

30. LaMonte MJ and Blair SN. Physical activity, cardiorespiratory fitness, and adiposity: Contributions to disease risk. Curr Opin Clin Nutr Metab Care 9: 540-546, 2006.

31. Lankhorst K, van der Ende-Kastelijn K, de Groot J, Zwinkels M, Verschuren O, Backx F, et al. Health in Adapted Youth Sports Study (HAYS): Health effects of sports participation in children and adolescents with a chronic disease or physical disability. Springerplus 4: 796, 2015. 
Lankhorst, K., Takken, T., Zwinkels, M., Gaalen, L. van, Velde, S. te, Backx, F., Verschuren, O., Wittink, H., Groot, J. de. Sports Participation, Physical Activity, and Health-Related Fitness in Youth With Chronic Diseases or Physical Disabilities: The Health in Adapted Youth Sports Study. Journal of Strenght and Conditioning Research: 2019

32. Lankhorst K, Berg-Emons van den R, Bussmann J, Horemans H, and de Groot JF. A novel tool for quantifying and promote $g$ physical activity in youths with typical development and youths who are ambulatory and have motor disability. Phys Ther 99:1-10, 2019.

33. Lloyd RS, Cronin JB, Faigenbaum AD, Haff GG, Howard R, Kraemer WJ, et al. National Strength and Conditioning Association Position Statement on long-term athletic development. J Strength Cond Res 30: 1491-1509, 2016.

34. McManus AM and Armstrong N. Maximal oxygen uptake. Maximal Oxygen Uptake. In: Rowland, TW, ed. Cardiopulmonary Exercise Testing in Children and Adolescents. Champaign IL: Human Kinetics, 2018. pp. 79-94.

35. Montoye AH, Moore RW, Bowles HR, Korycinski R, and Pfeiffer KA. Reporting accelerometer methods in physical activity intervention studies: A systematic review and recommendations for authors. Br J Sports Med, 2016. Epub ahead of print. 36. Neter JE, Schokker DF, de Jong E, Renders CM, Seidell JC, and Visscher TL. The prevalence of overweight and obesity and its determinants in children with and without disabilities. J Pediatr 158: 735-739, 2011.

37. Ortega FB, Konstabel K, Pasquali E, Ruiz JR, Hurtig-Wennlo“ f A, Mäestu J, et al. Objectively measured physical activity and sedentary time during childhood, adolescence and young adulthood: A cohort study. PLoS One 8: e60871, 2013.

38. Poitras VJ, Gray CE, Borghese MM, Carson V, Chaput JP, Janssen I, et al. Systematic review of the relationships between objectively measured physical activity and health indicators in school-aged children and youth. Appl Physiol Nutr Metab 41(6 Suppl 3): S197-S239, 2016.

39. Riddoch CJ, Mattocks C, Deere K, Saunders J, Kirkby J, Tilling K, et al. Objective measurement of levels and patterns of physical activity. Arch Dis Child 92: 963-969, 2007.

40. Schoenmakers MA, de Groot JF, Gorter JW, Hillaert JL, Helders PJ, Takken T, et al. Muscle strength, aerobic capacity and physical activity in independent ambulating children with lumbosacral spina bifida. Disabil Rehabil 31: 259-266, 2009.

41. Steenman K, Verschuren O, Rameckers E, Douma-van Riet D, and Takken T. Extended reference values for the muscle power sprint test in 6- to 18-year-old children. Pediatr Phys Ther 28: 78-84, 2016.

42. Talma H. Growth Charts 2010: A Manual to Measure and Weigh Children and Completing Growth Charts.Delft, the Netherlands:TNO, 2010.

43. Te Velde SJ, Lankhorst K, Zwinkels M, Verschuren O, Takken T, and de Groot J. Associations of sport participation with self-perception, exercise self-efficacy and quality of life among children and adolescents with a physical disability or chronic disease-a cross-sectional study. Sports Med Open 4: 38, 2018.

44. Telford RM, Telford RD, Cochrane T, Cunningham RB, Olive LS, and Davey R. The influence of sport club participation on physical activity, fitness and body fat during childhood and adolescence: The LOOK Longitudinal Study. J Sci Med Sport 19: 400-406, 2016.

45. van Brussel M, van der Net J, Hulzebos E, Helders PJ, and Takken T. The Utrecht approach to exercise in chronic childhood conditions: The decade in review. Pediatr Phys Ther 23: 2-14, 2011.

46. Vella SA, Schranz NK, Davern M, Hardy LL, Hills AP, Morgan PJ, et al. The contribution of organised sports to physical activity in Australia: Results and directions from the Active Healthy Kids Australia 2014 Report Card on physical activity for children and young people. J Sci Med Sport 19: 407-412, 2016.

47. Verschuren $O$ and Takken T. Aerobic capacity in children and adolescents with cerebral palsy. Res Dev Disabil 31: 1352-1357, 2010.

48. Verschuren O, Takken T, Ketelaar M, Gorter JW, and Helders PJ. Reliability and validity of data for 2 newly developed shuttle run tests in children with cerebral palsy. Phys Ther 86: 1107$1117,2006$. 
Lankhorst, K., Takken, T., Zwinkels, M., Gaalen, L. van, Velde, S. te, Backx, F., Verschuren, O., Wittink, H., Groot, J. de. Sports Participation, Physical Activity, and Health-Related Fitness in Youth With Chronic Diseases or Physical Disabilities: The Health in Adapted Youth Sports Study. Journal of Strenght and Conditioning Research: 2019

49. Verschuren O, Ketelaar M, Gorter JW, Helders PJ, Uiterwaal CS, and Takken T. Exercise training program in children and adolescents with cerebral palsy: A randomized controlled trial. Arch Pediatr Adolesc Med 161: 1075-1081, 2007.

50. Verschuren O, Takken T, Ketelaar M, Gorter JW, and Helders PJ. Reliability for running tests for measuring agility and an aerobic muscle power in children and adolescents with cerebral palsy. Pediatr Phys Ther 19: 108-115, 2007.

51. VerschurenO, KetelaarM, Gorter JW, Helders PJ, and Takken T. Relation between physical fitness and gross motor capacity in children and adolescents with cerebral palsy. Dev Med Child Neurol 51: 866-871, 2009.

52. Verschuren O, Maltais DB, and Takken T. The 220-age equation does not predict maximum heart rate in children and adolescents. Dev Med Child Neurol 53: 861-864, 2011.

53. Verschuren $O$, Wiart L, Hermans D, and Ketelaar M. Identification of facilitators and barriers to physical activity in children and adolescents with cerebral palsy. J Pediatr 161: 488-494, 2012.

54. Verschuren O, Bongers BC, Obeid J, Ruyten T, and Takken T. Validity of the muscle power sprint test in ambulatory youth with cerebral palsy. Pediatr Phys Ther 25: 25-28, 2013.

55. Verschuren O, Maltais DB, Douma-van Riet D, Kruitwagen C, and Ketelaar M. Anaerobic performance in children with cerebral palsy compared to children with typical development. Pediatr Phys Ther 25: 409-413, 2013.

56. Vrijkotte S, de Vries S, and Jongert T. Fitheidstesten voor de jeugd (Vol. 031): TNO Kwaliteit van Leven, 2007. pp. 10038.

57. Winnick JP and Short FX, eds. Test Administration and Test Items. In: The Brockport Physical Fitness Test Manual. Champaign, IL: Human Kinetics, 1999. pp. 66-128.

58. ZwinkelsM, Takken T, Visser-Meily JMA, and Verschuren O. Effects of high-intensity interval training on fitness and health in youth with physical disabilities. Pediatr Phys Ther 31: 84-93, 2019.

\section{Tables and figures}

Table 1 Overview of the outcome measures and chosen measurement instruments in this study. *

\begin{tabular}{|c|c|c|c|}
\hline Outcome measure & Parameter & Variable & Measurement \\
\hline \multicolumn{4}{|l|}{ General } \\
\hline & Demographics & DOB, sex, and medical diagnosis & General questionnaire \\
\hline & & Activity level and participation in sports & \\
\hline \multicolumn{4}{|l|}{ Health-related fitness } \\
\hline \multirow[t]{6}{*}{ Cardiovascular health } & Metabolic & BMI & Height and body mass \\
\hline & & Body composition & Waist and hip circumference \\
\hline & & Fat mass & BIA \\
\hline & & Blood pressure & Arteriograph \\
\hline & & Arterial stiffness & Arteriograph \\
\hline & & Pulse wave velocity & Arteriograph \\
\hline \multirow[t]{7}{*}{ Physical fitness } & Muscle strength & Isometric muscle strength & Grip strength \\
\hline & & Explosive muscle strength & Standing broad jump \\
\hline & Agility & Time & $10 \times 5-\mathrm{m}$ sprint \\
\hline & Anaerobic fitness & Mean power & MPST \\
\hline & Aerobic fitness & $\dot{V}_{0_{2}}$ peak & CPET, shuttle run test or bicycle test, and Godfrey protocol \\
\hline & & RER & \\
\hline & & Heart rate & \\
\hline \multicolumn{4}{|l|}{ Physical activity } \\
\hline & Modality & Type of activity & Activity monitor (Activ8) and activity diary \\
\hline
\end{tabular}


Lankhorst, K., Takken, T., Zwinkels, M., Gaalen, L. van, Velde, S. te, Backx, F., Verschuren, O., Wittink, H., Groot, J. de. Sports Participation, Physical Activity, and Health-Related Fitness in Youth With Chronic Diseases or Physical Disabilities: The Health in Adapted Youth Sports Study. Journal of Strenght and Conditioning Research: 2019

Table 2 Eligibility and exclusion criteria.

\begin{tabular}{ll}
\hline Eligibility & \multicolumn{1}{c}{ Exclusion } \\
\hline $\begin{array}{l}\text { Children and adolescents with a physical disability or chronic disease } \\
\text { Cardiovascular, pulmonary, musculoskeletal, or neuromuscular disorder }\end{array}$ & $\begin{array}{l}\text { Children and adolescents with progressive diseases } \\
\text { Children and adolescents using a wheelchair as main mode of mobility } \\
\text { Children and adolescents between the age of } 8 \text { and } 19 \text { years }\end{array}$ \\
$\begin{array}{ll}\text { During the length of the study, children were not allowed to participate in other research } \\
\text { projects, which might influenced the current study results }\end{array}$ \\
$\begin{array}{l}\text { For the sporting group of the HAYS study only, subjects who have not participated in any } \\
\text { sports for the preceding } 3 \text { months }\end{array}$ \\
Children and adolescents who were able to perform physical fitness tests
\end{tabular}


Lankhorst, K., Takken, T., Zwinkels, M., Gaalen, L. van, Velde, S. te, Backx, F., Verschuren, O., Wittink, H., Groot, J. de. Sports Participation, Physical Activity, and Health-Related Fitness in Youth With Chronic Diseases or Physical Disabilities: The Health in Adapted Youth Sports Study. Journal of Strenght and Conditioning Research: 2019

Table 3 Characteristics of the nonsport group (NSG) and sport group (SG).*.

\begin{tabular}{|c|c|c|c|c|}
\hline & Total, $N=163$ & Nonsport group (SD) $N=82$ & Sport group (SD) $N=81$ & $p$ \\
\hline Boys/girls† & $96 / 67$ & $38 / 44$ & $58 / 23$ & $0.001 \S$ \\
\hline Age in yearsł & & $14.31(3.1)$ & $14.15(2.7)$ & 0.725 \\
\hline Diagnose group in \%† & & 0.532 & & \\
\hline Cardiovascular disease & 12.9 & 17.1 & 8.6 & \\
\hline Pulmonary disease & 4.9 & 3.7 & 6.2 & \\
\hline Metabolic disease & 9.8 & 8.5 & 11.1 & \\
\hline Musculoskeletal/orthopedic disability & 6.1 & 4.9 & 7.4 & \\
\hline Neuromuscular disorder & 49.1 & 51.2 & 46.9 & \\
\hline Immunological/hematological disease & 10.4 & 11.0 & 9.9 & \\
\hline Cancer & 1.8 & 1.2 & 2.5 & \\
\hline Epilepsy & 4.9 & 2.4 & 7.4 & \\
\hline
\end{tabular}

*Age is presented as mean and $S D$, the diagnose group is presented as percentages with the pvalues from the $t$-test for independent samples for continuous variables with normal distribution. Diagnose group classifications according to the guidelines of the American College of Sports Medicine (17).

TThe chi-square test for sex and prevalence of diseases or disabilities.

†TheMann-Whitney U-test for continuous variables with skewed distribution.

$\S$ Significant difference

Figure 1 Mediation analysis.

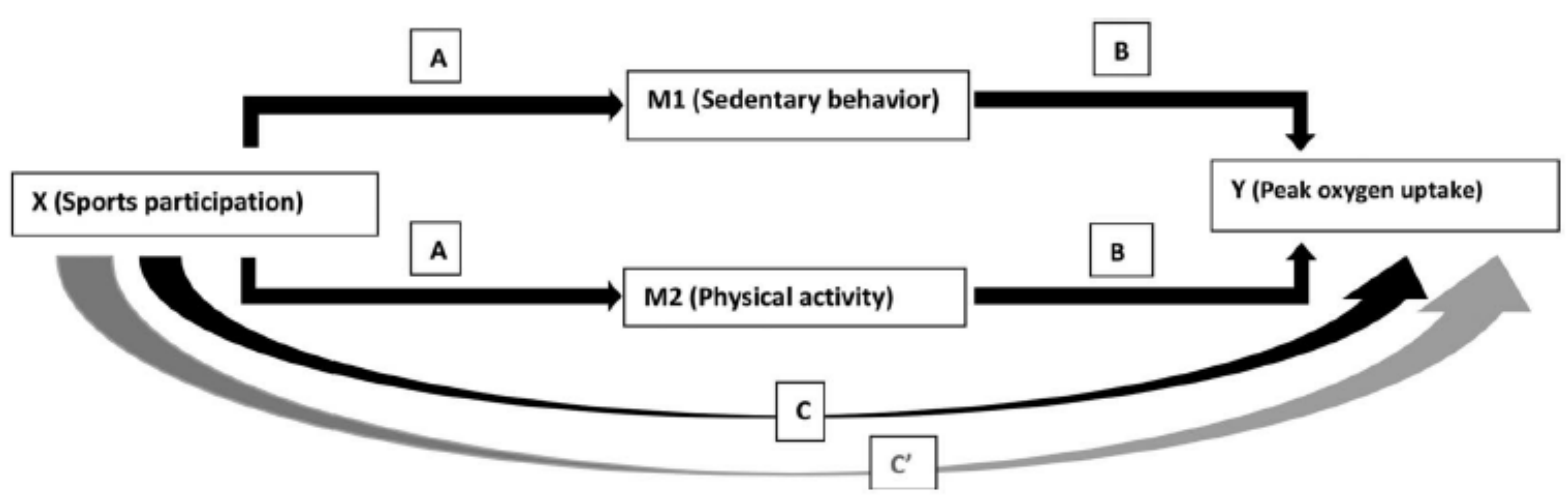


Lankhorst, K., Takken, T., Zwinkels, M., Gaalen, L. van, Velde, S. te, Backx, F., Verschuren, O., Wittink, H., Groot, J. de. Sports Participation, Physical Activity, and Health-Related Fitness in Youth With Chronic Diseases or Physical Disabilities: The Health in Adapted Youth Sports Study. Journal of Strenght and Conditioning Research: 2019

Table 4 Health-related fitness in relation to outcome variables of the nonsport group (NSG) and sport group (SG).*†

\begin{tabular}{|c|c|c|c|}
\hline Metabolic variables, $N=162$ & NSG $(S D), N=81$ & $\mathrm{SG}(S D), N=81$ & $p$ \\
\hline Body mass index $\left(\mathrm{kg} \cdot \mathrm{m}^{-2}\right)$ & $21.28(4.82)$ & $20.33(3.72)$ & 0.159 \\
\hline Body mass index $\left(\mathrm{kg} \cdot \mathrm{m}^{-2}\right)$ SDS & $0.75(1.55)$ & $0.61(1.23)$ & 0.537 \\
\hline Waist circumference $(\mathrm{cm})$ & $77.16(14.4)$ & $74.4(12.2)$ & 0.195 \\
\hline Waist circumference SDS & $1.05(1.4)$ & $0.72(1.26)$ & 0.123 \\
\hline Hip circumference (cm) & $87.6(12.5)$ & 86.9 (11.2) & 0.696 \\
\hline Hip circumference SDS & $0.40(1.34)$ & $0.41(1.11)$ & 0.937 \\
\hline Waist/hip ratio & $0.88(0.10)$ & $0.86(0.08)$ & 0.087 \\
\hline Waist/hip ratio SDS & $1.17(1.38)$ & $0.63(1.40)$ & $0.013 \S$ \\
\hline Fat mass $(\%)$ & $25.4(9.2)$ & $20.8(8.1)$ & $0.001 \S$ \\
\hline Aerobic fitness variables, $N=151 \|$ & NSG $(S D), N=74$ & $\mathrm{SG}(S D), N=77$ & $p$ \\
\hline Peak oxygen uptake $\left(L \cdot \min ^{-1}\right)$ & $2.16(0.7)$ & $2.48(0.9)$ & $0.019 \S$ \\
\hline Peak oxygen uptake $\left(L \cdot \min ^{-1}\right)$ SDS & $-0.91(1.3)$ & $-0.29(1.3)$ & $0.005 \neq \S$ \\
\hline Peak oxygen uptake $\left(\mathrm{ml} \cdot \mathrm{kg}^{-1} \cdot \mathrm{min}^{-1}\right)$ & $39.2(7.7)$ & $45.6(9.6)$ & $0.000 \neq \S$ \\
\hline Peak oxygen uptake $\left(\mathrm{ml} \cdot \mathrm{kg}^{-1} \cdot \mathrm{min}^{-1}\right) \mathrm{SDS}$ & $-0.97(1.3)$ & $-0.21(1.5)$ & $0.001 \neq \S$ \\
\hline Maximal heart rate & $191(10.6) n=72$ & $192(12.5)$ & 0.723 \\
\hline RER & $1.10(0.07)$ & $1.10(0.10)$ & 0.943 \\
\hline Cardiovascular variables, $N=160$ & NSG $(S D), N=79$ & SG $(S D), N=79$ & $p$ \\
\hline Systolic blood pressure (mm Hg) & $124.5(14.0)$ & $126.8(16.6)$ & 0.348 \\
\hline Diastolic blood pressure (mm Hg) & $69.1(10.1)$ & $67.7(10.3)$ & 0.392 \\
\hline AIX (\%) & $9.5(8.3) n=76$ & $8.3(6.8) n=76$ & 0.331 \\
\hline $\mathrm{PW}\left(\mathrm{m} \cdot \mathrm{s}^{-1}\right)$ & $6.1(0.9) n=76$ & $5.8(0.9) n=76$ & 0.119 \\
\hline Resting heart frequency & $71(11.0) n=75$ & $69(12.3) n=81$ & 0.334 \\
\hline Motor variables, $N=160$ & $\operatorname{NSG}(S D), N=82$ & $\mathrm{SG}(S D), N=78$ & $p$ \\
\hline MPST—mean power (watt) & $230.9(145.6)$ & $301.7(180.7)$ & $0.007 \pm \S$ \\
\hline $10 \times 5(\mathrm{sec})$ & $24.2(4.7)$ & $22.0(4.6) n=77$ & $0.003 \S$ \\
\hline Mean grip strength (newton) & $212.5(114.4)$ & $267.9(127.1) n=77$ & $0.004 \S$ \\
\hline Mean standing broad jump (cm) & $103.5(39.8) n=81$ & $124.9(41.5) n=78$ & $0.001 \S$ \\
\hline
\end{tabular}

Table 5 Objective measured physical activity during school days and weekend days in the nonsport group (NSG) and sport group (SG).*

\begin{tabular}{|c|c|c|c|}
\hline Physical activity during school days in minutes per day; $N=126$ & NSG $(S D), N=65$ & $\mathrm{SG}(S D), N=61$ & $p$ \\
\hline Sedentary time (lying-sitting) & $588.0(89.2)$ & $581.0(71.1)$ & 0.627 \\
\hline Lying & $4.3(6.8)$ & $6.1(11.7)$ & 0.301 \\
\hline Sitting & $583.7(88.7)$ & $574.9(72.8)$ & 0.546 \\
\hline Standing & $115.7(43.8)$ & $119.2(42.0)$ & 0.651 \\
\hline Active time (walking-cycling-running) & $155.9(50.0)$ & $186.8(44.0)$ & $0.000 \ddagger$ \\
\hline Walking & $128.0(42.3)$ & $141.7(43.4)$ & 0.074 \\
\hline Oycling & $24.8(24.5)$ & $37.5(25.0)$ & $0.005 \ddagger$ \\
\hline Running & $3.1(3.2)$ & $7.5(5.3)$ & $0.000 \dagger \ddagger$ \\
\hline Physical activity during weekend days in minutes per day; $N=116$ & NSG $(S D), N=59$ & $S G(S D), N=57$ & p \\
\hline Sedentary time (lying-sitting) & $543.2(100.8)$ & $561.8(102.7)$ & 0.327 \\
\hline Lying & $6.0(9.4)$ & $11.6(20.9)$ & $0.060 \dagger$ \\
\hline Sitting & $537.2(100.3)$ & $550.1(101.2)$ & 0.490 \\
\hline Standing & $119.2(57.5)$ & $123.2(47.3)$ & 0.681 \\
\hline Active time (walking-cycling-running) & $134.3(62.9)$ & $159.0(62.0)$ & $0.035 \ddagger$ \\
\hline Walking & $115.4(57.1)$ & $123.6(53.3)$ & 0.424 \\
\hline Oycling & $17.3(14.6)$ & $28.4(24.1)$ & $0.004 \dagger \ddagger$ \\
\hline Running & $1.6(2.0)$ & $7.0(8.2)$ & $0.000 \dagger \ddagger$ \\
\hline
\end{tabular}

"Outcome variables are presented as mean and $S D$ s with the $p$ values from the Student's $t$-testfor independent samples for continuous variables vith normal distribution. Criteria for analysis: (a) $>600$ minutes awake time per day and (b) at least one measured weekend day and at least 2 school days.

†Equal variances not assumed.

$\ddagger$ Statistical difference. 
Lankhorst, K., Takken, T., Zwinkels, M., Gaalen, L. van, Velde, S. te, Backx, F., Verschuren, O., Wittink, H., Groot, J. de. Sports Participation, Physical Activity, and Health-Related Fitness in Youth With Chronic Diseases or Physical Disabilities: The Health in Adapted Youth Sports Study. Journal of Strenght and Conditioning Research: 2019

Table 6 Associations of sports participation with health-related fitness in youth with chronic diseases or physical disabilities. ${ }^{*}+$

\begin{tabular}{|c|c|c|c|c|}
\hline Health-related fitness & B $(S D)$ & $95 \% \mathrm{Cl}$ & $p$ & Adjusted $\boldsymbol{R}$ square \\
\hline \multicolumn{5}{|c|}{ Peak oxygen uptake $\left(\mathrm{ml} \cdot \mathrm{kg}^{-1} \cdot \mathrm{min}^{-1}\right) ; N=151$} \\
\hline Constant & $42.438(1.215)$ & 40.036 to 44.840 & $0.000^{*}$ & \\
\hline Sports participation & $4.891(1.389)$ & 2.145 to 7.636 & $0.001^{*}$ & \\
\hline Sex & $-6.242(1.419)$ & -9.046 to -3.437 & $0.000^{*}$ & 0.213 \\
\hline \multicolumn{5}{|c|}{ Peak oxygen uptake $\left(L \cdot \min ^{-1}\right) ; N=151$} \\
\hline Constant & $-0.125(0.252)$ & -6.23 to 3.74 & 0.622 & \\
\hline Sports participation & $0.248(0.094)$ & 0.062 to 0.433 & $0.009^{*}$ & \\
\hline Sex & $-0.667(0.095)$ & -0.856 to -0.478 & $0.000^{\star}$ & \\
\hline Age in years & $0.180(0.016)$ & -0.148 to 0.212 & $0.000^{*}$ & 0.559 \\
\hline \multicolumn{5}{|c|}{ MPST—mean power (W); $N=160$} \\
\hline Constant & $-175.516(46.409)$ & -267.191 to -83.841 & $0.000^{*}$ & \\
\hline Sports participation & $41.203(17.872)$ & 5.899 to 76.508 & $0.022^{*}$ & \\
\hline Sex & $-124.794(18.104)$ & -160.556 to -89.032 & $0.000^{*}$ & \\
\hline Age in years & $35.245(2.983)$ & 29.355 to 41.135 & $0.000^{*}$ & \\
\hline Motoric gait function & $-60.422(17.263)$ & -94.523 to -26.322 & $0.001^{\star}$ & 0.575 \\
\hline \multicolumn{5}{|c|}{$10 \times 5$-m sprint test $(\mathrm{sec}) ; N=159$} \\
\hline Constant & 31.924 (1.602) & 28.759 to 35.089 & $0.000^{*}$ & \\
\hline Sports participation & $-1.718(0.617)$ & 28.759 to 35.099 & $0.006^{\star}$ & \\
\hline Sex & $1.719(0.626)$ & 0.483 to 2.956 & $0.007^{*}$ & \\
\hline Age in years & $-0.724(0.103)$ & -0.927 to -0.521 & $0.000^{*}$ & \\
\hline Motoric gait function & $3.424(0.594)$ & 2.250 to 4.597 & $0.000^{\star}$ & 0.389 \\
\hline \multicolumn{5}{|c|}{ Mean grip strength (newton); $N=159$} \\
\hline Constant & $-90.542(35.263)$ & -160.203 to -20.880 & $0.011^{*}$ & \\
\hline Sports participation & $40.384(13.584)$ & 13.549 to 67.219 & $0.003^{*}$ & \\
\hline Sex & $-59.404(13.751)$ & -86.569 to -32.240 & $0.000^{*}$ & \\
\hline Age in years & $25.965(2.263)$ & 21.493 to 30.436 & $0.000^{*}$ & \\
\hline Motoric gait function & $-71.497(13.131)$ & -97.436 to -45.557 & $0.000^{\star}$ & 0.553 \\
\hline \multicolumn{5}{|c|}{ Mean standing broad jump (cm); $N=157$} \\
\hline Constant & $44.308(12.477)$ & 19.657 to 68.960 & $0.001^{*}$ & \\
\hline Sports participation & $17.447(4.801)$ & 7.962 to 26.933 & $0.000^{\star}$ & \\
\hline Sex & $-23.056(4.857)$ & -32.652 to -13.459 & $0.000^{*}$ & \\
\hline Age in years & $6.224(0.805)$ & 4.634 to 7.814 & $0.000^{*}$ & \\
\hline Motoric gait function & $-35.073(4.652)$ & -44.264 to -25.882 & $0.000^{\star}$ & 0.504 \\
\hline \multicolumn{5}{|l|}{ Fat mass $(\%)$} \\
\hline Constant & 25.740 (3.369) & 19.086 to 32.394 & $0.000^{*}$ & \\
\hline Sports participation & $-3.303(1.285)$ & -5.840 to -0.765 & $0.011^{\star}$ & \\
\hline Sex & 4.583 (1.303) & 2.009 to 7.157 & $0.001^{\star}$ & \\
\hline Age in years & $-0.395(0.216)$ & -0.821 to 0.031 & $0.069^{\star}$ & \\
\hline Motoric gait function & 5.777 (1.239) & 3.131 to 8.024 & $0.000^{\star}$ & 0.223 \\
\hline \multicolumn{5}{|l|}{ Waist/hip ratio SDS } \\
\hline Constant & $0.968(0.035)$ & 0.900 to 1.036 & $0.000^{*}$ & \\
\hline Sports participation & $-0.033(0.013)$ & -0.059 to -0.007 & $0.014^{\star}$ & \\
\hline Sex & $-0.037(0.013)$ & -0.064 to -0.011 & $0.006^{\star}$ & \\
\hline Age in years & $-0.007(0.002)$ & -0.011 to -0.002 & $0.003^{*}$ & \\
\hline Motoric gait function & $0.056(0.013)$ & 0.031 to 0.081 & $0.000^{\star}$ & 0.178 \\
\hline
\end{tabular}

“MPST $=$ muscle power sprint test; $S D S=S D$ scores (Z score).

tThe data are standardized regression coefficients (B) with $S D$ and their $95 \%$ confidence intervals (Cls), p values, and explained variance (adjusted $R$ square). Outcome variables are adjusted for sports participation, sex, age, and motoric gait function. 
Lankhorst, K., Takken, T., Zwinkels, M., Gaalen, L. van, Velde, S. te, Backx, F., Verschuren, O., Wittink, H., Groot, J. de. Sports Participation, Physical Activity, and Health-Related Fitness in Youth With Chronic Diseases or Physical Disabilities: The Health in Adapted Youth Sports Study. Journal of Strenght and Conditioning Research: 2019

Tabel 7 Associations of sports participation with physical activity in youth with chronic diseases or physical disabilities. ${ }^{*}+$

\begin{tabular}{|c|c|c|c|c|}
\hline Mean PA during school days in minutes per day; $N=126$ & $\mathrm{~B}(S D)$ & $95 \% \mathrm{Cl}$ & $p$ & Adjusted $\boldsymbol{R}$ square \\
\hline \multicolumn{5}{|l|}{ Cycling } \\
\hline Constant & $30.491(3.907)$ & 22.758 to 38.225 & $0.000^{*}$ & \\
\hline Sports participation & $11.956(4.351)$ & 3.343 to 20.569 & $0.007^{\star}$ & \\
\hline Motoric gait function & $-9.965(4.358)$ & -18.590 to -1.339 & $0.024^{\star}$ & 0.087 \\
\hline \multicolumn{5}{|l|}{ Running } \\
\hline Constant & $11.210(1.871)$ & 7.506 to 14.914 & $0.000^{\star}$ & \\
\hline Sports participation & $4.187(0.744)$ & 2.715 to 5.659 & $0.000^{*}$ & \\
\hline Sex & $-1.724(0.752)$ & -3.212 to -0.245 & $0.024^{*}$ & \\
\hline Age in years & $-0.511(0.125)$ & -0.759 to -0.264 & $0.000^{\star}$ & 0.315 \\
\hline \multicolumn{5}{|l|}{ Active time (walking-cycling-running) } \\
\hline Constant & $167.933(7.418)$ & 153.250 to 182.616 & $0.000^{\star}$ & \\
\hline Sports participation & $29.321(8.261)$ & 12.968 to 45.674 & $0.001^{*}$ & \\
\hline Motoric gait function & $-21.228(8.274)$ & -37.605 to -4.850 & $0.012^{\star}$ & 0.130 \\
\hline Mean PA during weekend in minutes per day, $N=116$ & $\mathrm{~B}(S D)$ & $95 \% \mathrm{Cl}$ & $p$ & Adjusted $\boldsymbol{R}$ square \\
\hline \multicolumn{5}{|l|}{ Cycling } \\
\hline Constant & $37.658(9.628)$ & 18.583 to 56.733 & $0.000^{\star}$ & \\
\hline Sports participation & $11.368(3.627)$ & 4.182 to 18.555 & $0.002^{\star}$ & \\
\hline Age in years & $-1.429(0.653)$ & -2.722 to -0.137 & $0.031^{\star}$ & 0.095 \\
\hline \multicolumn{5}{|l|}{ Running } \\
\hline Constant & $1.563(0.770)$ & 0.038 to 3.089 & $0.045^{\star}$ & \\
\hline Sports participation & $5.452(1.099)$ & 3.275 to 7.628 & $0.000^{*}$ & 0.170 \\
\hline \multicolumn{5}{|l|}{ Active time (walking-cycling-running) } \\
\hline Constant & $246.000(28.966)$ & 168.613 to 303.386 & $0.000^{\star}$ & \\
\hline Sports participation & $26.488(10.913)$ & 4.868 to 48.108 & $0.017^{\star}$ & \\
\hline Age in years & $-7.851(1.963)$ & -11.731 to -3.961 & $0.000^{\star}$ & \\
\hline
\end{tabular}

*PA = physical activity.

†The data are standardized regression coefficients (B) with SD and their 95\% confidence intervals (Cls), $p$ values, and explained variance (adjusted $R$ square). Outcome variables are adjusted for sports participation, sex, age, and motoric gait function.

Table 8 Mediation analysis: association between sports participation (yes/no) and $\dot{V}^{2}$ peak via the mediator variables of sedentary behavior and physical activity (N 5 106).*†

\begin{tabular}{|c|c|c|c|c|c|c|c|c|c|c|c|}
\hline Mediator & Measure & $\begin{array}{c}\text { A } \\
\text { coefficient } \\
(S E)\end{array}$ & $p$ & $\begin{array}{c}\text { B coefficient } \\
(S E)\end{array}$ & $p$ & $\begin{array}{c}\text { C } \\
\text { coefficient } \\
(S E)\end{array}$ & $p$ & $\begin{array}{c}C^{\prime} \\
\text { coefficient } \\
(S E)\end{array}$ & $p$ & $\begin{array}{l}\text { Mediated effect } \\
(\mathrm{a} \times \mathrm{b})(95 \% \mathrm{Cl})\end{array}$ & $\begin{array}{c}\text { Proportion } \\
\text { mediated }\end{array}$ \\
\hline $\begin{array}{l}\text { M1 = sedentary behavior } \\
\left(\min \cdot \mathrm{wk}^{-1}\right)\end{array}$ & $\dot{\mathrm{V}}_{2}$ peak & $10.3(30.0)$ & 0.732 & $0.008(0.01)$ & 0.203 & & & & & $0.09(-0.34$ to 1.13$)$ & 0.02 \\
\hline $\begin{array}{l}\text { M2 = physical activity } \\
\left(\min \cdot \mathrm{wk}^{-1}\right)\end{array}$ & $\mathrm{V}_{2}$ peak & $46.8(17.68)$ & 0.009 & $0.033(0.01)$ & 0.003 & $5.044(1.65)$ & 0.003 & $3.406(1.69)$ & 0.045 & 1.55 (0.33 to 3.65$)$ & 0.31 \\
\hline
\end{tabular}

* $\dot{V}_{0_{2} \text { peak }}=$ peak oxygen uptake; $\mathrm{Q}=$ bootstrapped confidence interval. Bold = statistical significance.

tA coefficient refers to the effect of sports participation on the mediator variable (total minutes of sedentary behavior or physical activity during 1 week): B coefficient refers to the effect of the mediator variable

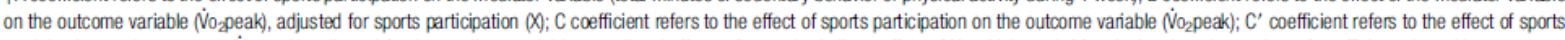
participation on the outcome ( $\mathrm{N}_{2}$ peak), adjusted for the mediator variables; mediated effect refers to the indirect effect of $\mathrm{X}$ on $\mathrm{Y}$ through $\mathrm{M}$, calculated as the product of coefficients $(\mathrm{a} \times \mathrm{b})$. $\ddagger$ All models were adjusted for sex, age, and motoric gait function. 